\title{
Chemical Characterization and Release Efficiency of Defatted Mustard Meals
}

Subcontract Report NREL/SR-510-36208 July 2005

2000-2002

M.J. Morra

University of Idaho

Moscow, Idaho

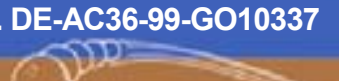




\section{Chemical Characterization and Release Efficiency of Defatted Mustard Meals}

2000-2002

M.J. Morra

University of Idaho

Moscow, Idaho

NREL Technical Monitor: K. Shaine Tyson

Prepared under Subcontract No. XC0-9-29095-01

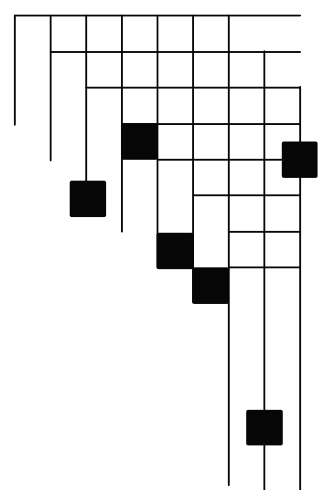




\section{NOTICE}

This report was prepared as an account of work sponsored by an agency of the United States government. Neither the United States government nor any agency thereof, nor any of their employees, makes any warranty, express or implied, or assumes any legal liability or responsibility for the accuracy, completeness, or usefulness of any information, apparatus, product, or process disclosed, or represents that its use would not infringe privately owned rights. Reference herein to any specific commercial product, process, or service by trade name, trademark, manufacturer, or otherwise does not necessarily constitute or imply its endorsement, recommendation, or favoring by the United States government or any agency thereof. The views and opinions of authors expressed herein do not necessarily state or reflect those of the United States government or any agency thereof.

Available electronically at http://www.osti.gov/bridge

Available for a processing fee to U.S. Department of Energy and its contractors, in paper, from:

U.S. Department of Energy

Office of Scientific and Technical Information

P.O. Box 62

Oak Ridge, TN 37831-0062

phone: 865.576 .8401

fax: 865.576 .5728

email: mailto:reports@adonis.osti.gov

Available for sale to the public, in paper, from:

U.S. Department of Commerce

National Technical Information Service

5285 Port Royal Road

Springfield, VA 22161

phone: 800.553 .6847

fax: 703.605.6900

email: orders@ntis.fedworld.gov

online ordering: http://www.ntis.gov/ordering.htm

This publication received minimal editorial review at NREL 


\section{Table of Contents}

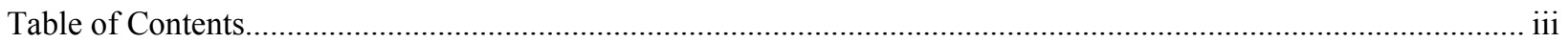

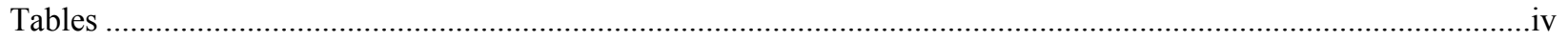

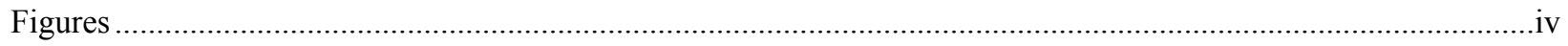

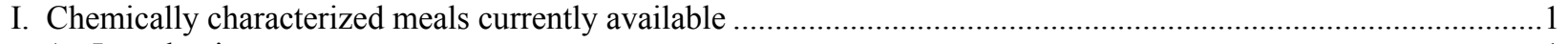

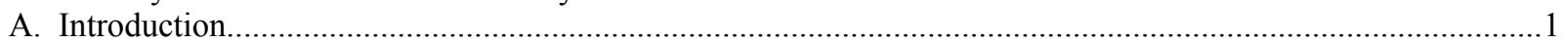

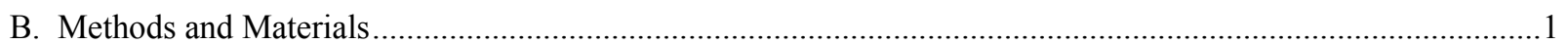

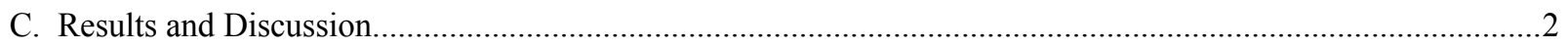

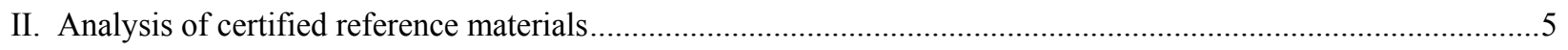

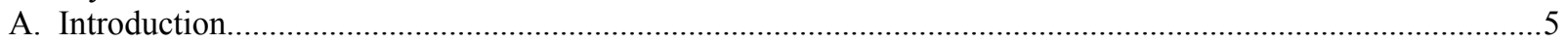

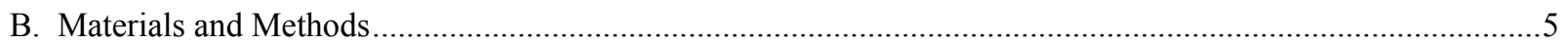

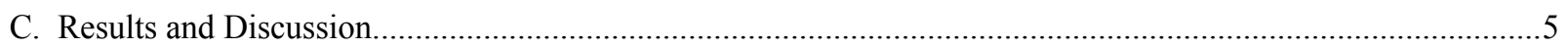

III. Methodology effects on total glucosinolate extractions ................................................................................

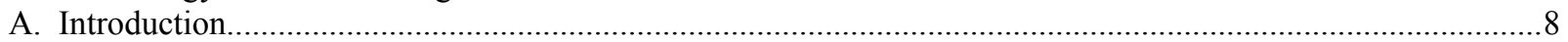

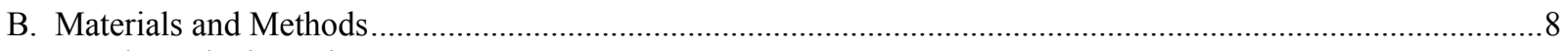

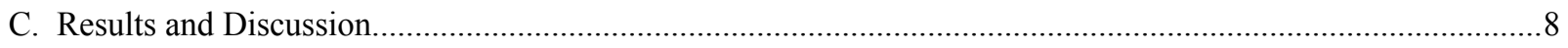

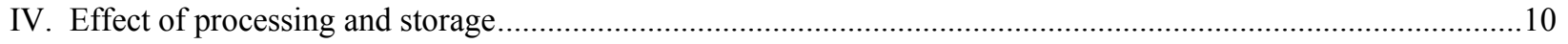

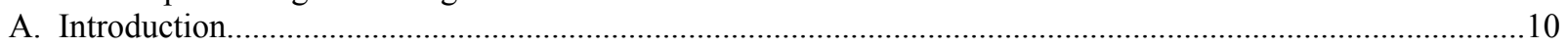

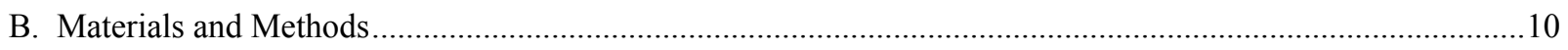

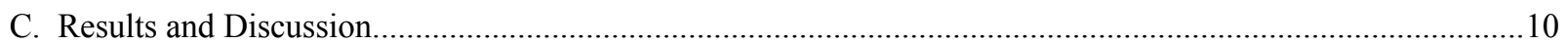

V. Isolation of glucotropeaolin (benzyl glucosinolate) from seeds of water cress …...............................................12

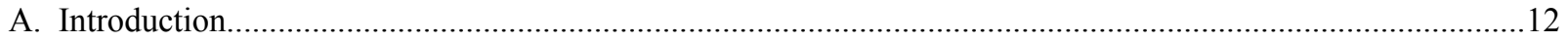

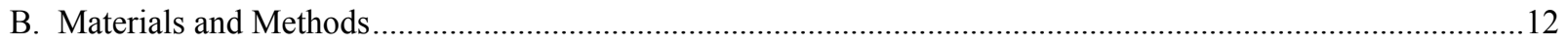

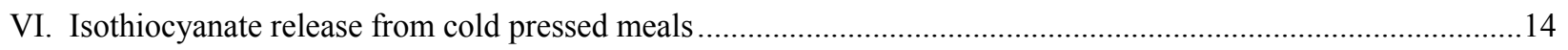

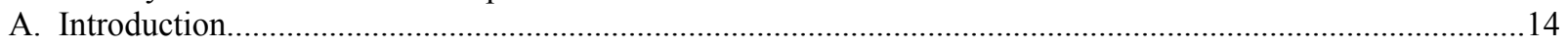

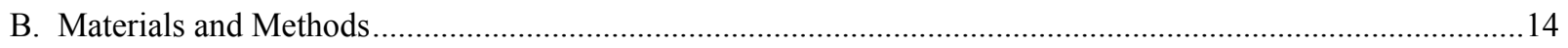

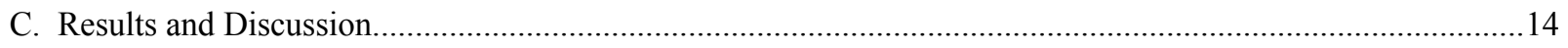

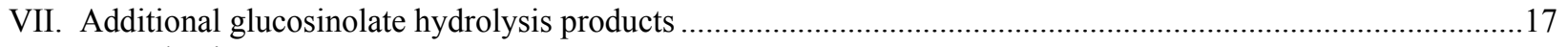

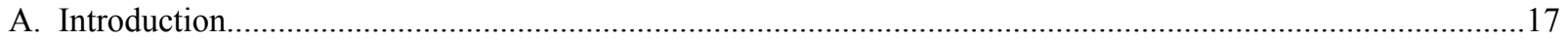

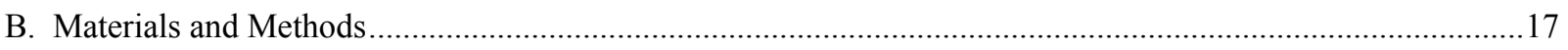

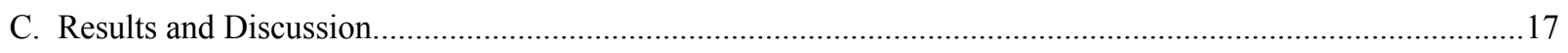

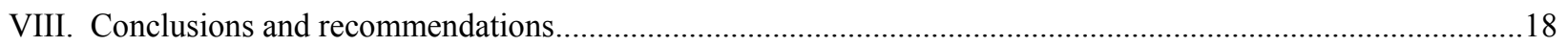




\section{Tables}

Table 1. Glucosinolate content of cold pressed seed meals ${ }^{1}$.

Table 2. Glucosinolate concentration comparisons between certified values and those determined in our laboratory for four B. napus samples. ${ }^{1}$

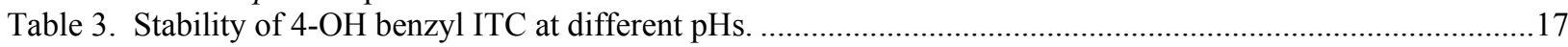

\section{Figures}

Figure 1. Glucosinolate concentrations in various meals as determined using hot water (ht) and methanol (me)

extraction. . .9

Figure 2. Comparison of total glucosinolates in stored, pelletized, or freshly pressed meal. ...................................11

Figure 3. Isothiocyanate (ITC) formation from three meal products. 


\section{CHEMICALLY CHARACTERIZED MEALS CURRENTLY AVAILABLE}

\section{A. Introduction}

Glucosinolates, compounds that occur in agronomically important crops, may represent a viable source of allelochemic control for various soil-borne plant pests. Toxicity is not attributed to intact glucosinolates, but instead to biologically active products such as isothiocyanates (ITCs), organic cyanides, oxazolidinethiones, and ionic thiocyanate $\left(\mathrm{SCN}^{-}\right)$released upon enzymatic degradation by myrosinase (thioglucoside glucohydrolase, EC 3.2.3.1) in the presence of water.

ITCs have historically been considered the "normal" products of glucosinolate breakdown. They are often volatile with pungent flavors or odors. The presence of propenyl ITC in mustards and horseradish is responsible for much of the flavor and thus, ITCs are sometimes called mustard oils. Formation requires that the initial unstable aglucon intermediate undergo a Loessen rearrangement to the $\mathrm{R}-\mathrm{N}=\mathrm{C}=\mathrm{S}$ configuration. Isothiocyanates are quite reactive, although less so than the related isocyanates $(\mathrm{R}-\mathrm{N}=\mathrm{C}=\mathrm{O})$. A few commercially available soil fumigants depend on the activity of methyl ITC either as the parent compound or as produced from precursors such as sodium N-methyldithiocarbamate or tetrahydro-3,5-dimethyl- $2 \mathrm{H}-1,3,5-$ thiadiazine-2-thione. Because of known toxicities, ITCs are often considered likely candidates for pesticidal activity.

We have proposed that meals with ITC-producing glucosinolate concentrations in excess of 200 $\mu \mathrm{mol} \mathrm{g}{ }^{-1}$ tissue will most effectively control of a wide variety of plant pests. The target is to produce in excess of $100 \mathrm{nmol} \mathrm{ITC} \mathrm{g}^{-1}$ soil in order to approach commercially recommended rates for synthetic ITC pesticides. Predictions of ITC release are based on realistic mealamendment rates and assumed conversion or release efficiencies of glucosinolates to ITCs. Our first goal was thus to quantify glucosinolate concentrations in the available meals to establish a benchmark that could be used for future breeding efforts.

In order to achieve such goals, accurate and precise methods for determination of glucosinolate concentrations in meal products are necessary. Standardized methods have been developed for rapeseed meal, but mustard meals present a much more challenging problem. Investigations have focused on the defining the critical areas that affect accuracy and precision of glucosinolate measurement in meals.

\section{B. Methods and Materials}

From the four meals selected for detailed chemical characterization replicate subsamples $(\sim 0.1 \mathrm{~g}$, recorded to the nearest $0.0001 \mathrm{~g}$ ) were prepared for extraction. Subsamples were placed into 15$\mathrm{mL}$ vials with 10-15 small glass beads at the bottom to help homogenization while the sample was being shaken. Vials were filled with $10-12 \mathrm{~mL}$ of methanol, capped, agitated on a vortexer for $30 \mathrm{~s}$, and allowed to stand at $22^{\circ} \mathrm{C}$ for $10 \mathrm{~min}$. Internal standard was added as $2 \mathrm{~mL}$ of 0.200

$\mu \mathrm{mol} \mathrm{mL} \mathrm{m}^{-1}$ propenyl glucosinolate (Sinigrin or "A") for Athena, Dwarf Essex, and IdaGold samples, while for Pacific Gold samples the internal standard added was $2 \mathrm{~mL}$ of $2.235 \mu \mathrm{mol}$ 
$\mathrm{mL}^{-1}$ benzyl glucosinolate (Glucotropaeolin - "B"). After the addition of internal standard, the samples were tightly capped, placed on a horizontal shaker for $40 \mathrm{~min}$, and centrifuged for 5 $\min$.

Ion exchange columns were prepared by placing them into a rack, adding $200 \mu \mathrm{L}$ of suspended DEAE Sephadex A25 material treated with $2 \mathrm{M}$ acetic acid, and rinsing twice with $2 \mathrm{~mL}$ of deionized (DI) water. Extract from each sample was carefully decanted into the ion exchange columns, allowed to drain, and rinsed twice with $2 \mathrm{~mL}$ of DI water. One milliliter of $0.02 \mathrm{M}$ ammonium acetate buffer ( $\mathrm{pH}$ 5.9) was added by pipette to each ion exchange column and allowed to drain. Sulfatase enzyme $(200 \mu \mathrm{L})$ was added to each ion exchange column using a pipette. An additional $200 \mu \mathrm{L}$ of $0.02 \mathrm{M}$ ammonium acetate buffer was added directly to each ion exchange column before the enzyme had drained. Each ion exchange column was loosely capped and allowed to incubate overnight $(\sim 15 \mathrm{~h})$. After incubation the desulfated glucosinolates were eluted by aligning the syringe tip of each ion exchange column into a set of labeled 2-mL glass vials. Each ion exchange column then received $1.5 \mathrm{~mL}$ of DI water and was allowed to drain. A gentle airflow (positive pressure from above) was applied to each vial until completely eluted.

The glass vials were capped with crimp-sealed aluminum caps and taken directly to the HPLC for analysis or otherwise stored in a refrigerator at $5^{\circ} \mathrm{C}$ until analysis. We used a Waters 2695 HPLC separation model with 996 PDA detector set at $229 \mathrm{~nm}$. The column was a Phenomenex Aqua $5 \mu \mathrm{C} 18125 \AA, 250 \times 2.00 \mathrm{~mm}$ and the mobile phase was water/methanol $0.5 \%$ to $50 \%$ with the flow rate set at $0.2 \mathrm{~mL} \mathrm{~min}^{-1}$.

\section{Results and Discussion}

The results for meal analysis are shown in Table 1. Four different meals were analyzed including 2 Brassica napus, $1 \mathrm{~B}$. juncea, and 1 Sinapis alba. Highest glucosinolate concentrations were measured in $S$. alba IdaGold meal with 4-OH benzyl showing as the dominant glucosinolate. The B. juncea variety Pacific Gold had the next highest glucosinolate concentration, with propenyl glucosinolate dominating the total. Literature references indicate that both 4-OH benzyl and propenyl glucosinolates produce ITC as an end product of hydrolysis at typical soil $\mathrm{pH}$ values. More recent evidence indicates that this assumption is not true for 4$\mathrm{OH}$ benzyl glucosinolate (see below). ITC production is significant since this compound is considered to be the most toxic of all glucosinolate hydrolysis products and thus most important in pest control. Recent results with weed seed bioassays have prompted us to reevaluate this assumption and consider the inhibitory properties of other compounds (data not shown). $B$. napus Dwarf Essex is dominated by 2-OH(R)-3-butenyl glucosinolate that does not produce ITC. Thus although total glucosinolate content of the meal is relatively high, it is less attractive from a pesticidal standpoint because ITC production is predicted to be approximately half of that for Pacific Gold. The remaining B. napus variety, Athena, was included because we routinely use this meal as an amendment in bioassay control experiments. We confirmed that only low glucosinolate concentrations were present. 
Table 1. Glucosinolate content of cold pressed seed meals ${ }^{1}$.

\begin{tabular}{|c|c|c|c|c|c|}
\hline Glucosinolate trivial name & Glucosinolate structure & $\begin{array}{l}\text { "Athena" } \\
\text { B. napus }\end{array}$ & $\begin{array}{c}\text { "Dwarf } \\
\text { Essex" } \\
\text { B. napus }\end{array}$ & $\begin{array}{l}\text { "Pacific Gold" } \\
\text { B. juncea }\end{array}$ & $\begin{array}{l}\text { "IdaGold" } \\
\text { S. alba }\end{array}$ \\
\hline Desulfoglucoiberin & 3-Me-SO-pentyl $1^{2}$ & $1.59 \pm 0.74$ & & & \\
\hline Desulfoprogoitrin & 2-OH(R)-3-butenyl & $6.08 \pm 0.29$ & $60.98 \pm 1.54$ & & \\
\hline Desulfoepi-progoitrin & 2-OH(S)-3-butenyl & & $1.03 \pm 0.23$ & & $6.38 \pm 0.09$ \\
\hline Desulfosinigrin & Propenyl $^{2}$ & & & $109.87 \pm 3.00$ & \\
\hline Desulfoglucoraphanin & 4-Me-SO-butyl ${ }^{2}$ & trace & trace & & $0.80 \pm 0.05$ \\
\hline Desulfonapoleiferin & 2-OH-4-pentenyl & trace & $3.55 \pm 0.23$ & & \\
\hline Desulfoglucosinalbin & 4-OH-benzyl $2^{2}$ & & & & $549.57 \pm 30.47$ \\
\hline Desulfoglucoalyssin & 4-Me-SO-pentyl $1^{2}$ & trace & $3.55 \pm 3.50$ & & \\
\hline Desulfogluconapin & 3-butenyl $1^{2}$ & $4.67 \pm 0.34$ & $41.40 \pm 4.23$ & & \\
\hline Desulfo-4- & 4-OH-indolyl-3- & $18.92 \pm 4.47$ & $5.48 \pm 1.05$ & $2.91 \pm 0.25$ & \\
\hline hydroxyglucobrassicin & methyl & & & & \\
\hline unknown & & & & & trace \\
\hline Desulfoglucobrassicanapin & 4-pentenyl ${ }^{2}$ & $1.17 \pm 0.04$ & $8.85 \pm 0.91$ & & \\
\hline Desulfoglucotropaeolin & $\begin{array}{l}\text { benzyl (4-Me-S- } \\
\text { butyl) })^{2}\end{array}$ & trace & $0.54 \pm 0.19$ & & \\
\hline Desulfoglucobrassicin & indolyl-3-methyl & $3.61 \pm 0.93$ & trace & & trace \\
\hline Desulfogluconasturtin & 2-phenylethyl ${ }^{2}$ & trace & $2.42 \pm 0.31$ & & \\
\hline & 4-MeO-indolyl-3- & trace & $0.43 \pm 0.01$ & $1.67( \pm 0.10)$ & \\
\hline methoxyglucobrassicin & methyl & & & & \\
\hline unknown & & trace & & $1.34( \pm 0.08)$ & \\
\hline \multirow[t]{3}{*}{ Desulfoneoglucobrassicin } & $\begin{array}{l}\text { N-MeO-indolyl-3- } \\
\text { methyl }\end{array}$ & trace & $0.86 \pm 0.2$ & & \\
\hline & TOTAL & $36.04 \pm 4.06$ & $129.09 \pm 7.13$ & $115.79( \pm 3.12)$ & $556.75 \pm 29.69$ \\
\hline & ITC-producing & 7.43 & 56.76 & 109.87 & 550.75 \\
\hline
\end{tabular}

${ }^{1}$ All values expressed in units of $\mu \mathrm{mol} \mathrm{g} \mathrm{g}^{-1}$ of sample (parentheses values are the standard deviation of the sample set). All reported

values are the average of 12 replications from three analysis runs. All meals analyzed were completely defatted and freeze-dried prior to extraction procedure.

${ }^{2}$ Isothiocyanate-producing glucosinolates;ITC- Isothiocyanate. 
Absolute ITC concentrations indicate that $S$. alba meal may show large pesticidal impacts because the ITC-producing glucosinolate concentration is in excess of $500 \mu \mathrm{mol} \mathrm{g}^{-1}$ meal. Glucosinolate concentrations of $B$. juncea meal are lower than anticipated and it is desirable to increase glucosinolate concentration closer to the $250 \mu \mathrm{mol} \mathrm{g}{ }^{-1}$ value as recommended in our literature review. However, the volatility, water solubility, and biological activity of the ITC produced from each of these glucosinolates must be considered before definitive conclusions of pesticidal activity can be made. Current results in bioassay experiments with fungus gnats and Fusarium oxysporum clearly show that $B$. juncea meal has a much greater pesticidal activity than $S$. alba despite $S$. alba's higher glucosinolate concentration. Although this is true for the two current bioassay organisms, other plant pests such as weeds show a completely different response. It thus appears that $S$. alba will be ineffective with respect to the control of insects, nematodes, and fungi, but that this species with its 4-OH benzyl glucosinolate acts as an effective herbicide. Bioassay data to support these assertions will be presented in another report. Chemical data to explain bioassay observations are presented below. In summary, total glucosinolate concentrations are not in themselves adequate predictors of pesticidal activity. The specific glucosinolate must be determined and a clear understanding of hydrolytic products is necessary. 


\section{ANALYSIS OF CERTIFIED REFERENCE MATERIALS}

\section{A. Introduction}

Analyses are under way to confirm the accuracy of our methodology. We have obtained rapeseed (BCR-190R, -366R and -367R rapeseed (colza) materials) with certification of total glucosinolate content as well as the mass fraction of individual glucosinolates from the European Commission, Joint Research Centre, Institute for Reference Materials and Measurements, Geel, Belgium. We are in the process of duplicating methodology found in the ISO (the International Organization for Standardization) 9167-1 report (Rapeseed - Determination of glucosinolates content).

\section{B. Materials and Methods}

We utilized the ISO (International Organization for Standardization) report 9167-1 titled "Rapeseed - Determination of glucosinolates content, Part 1: Method using high-performance liquid chromatography" as a guideline in the analysis of glucosinolates using HPLC. Certified reference materials were obtained from the European Commission, Joint Research Centre, Institute for Reference Materials and Measurements, in Geel, Belgium. We were provided with two low and two relatively high total glucosinolate varieties of whole rapeseed (c065, $\mathrm{c} 066$ and c635, c639; respectively). Included with these reference materials was the report EUR 19764 EN titled "The certification of the total glucosinolate and sulphur content of three rapeseed (colza) materials". Sample preparation, glucosinolate extraction, and HPLC analysis were conducted using the methodology as previously described.

\section{Results and Discussion}

Table 2 shows glucosinolate concentrations we measured in the reference seed materials as compared to certified glucosinolate concentrations for that respective sample. Comparison of the reported values and the results of our analyses are complicated by several factors. The reported values are expressed for whole seed and no correction for moisture content was made. In order to prepare the raw reference material for extraction, all moisture and oil was removed from the seed by finely grinding the seed and rinsing the resulting meal on filter paper with petroleum ether. The oil was removed by placing the filter paper into a Buchner funnel with a vacuum trap and applying a gentle negative pressure. Once all visible oil was removed, the defatted meal on filter paper was placed into a freeze-drier and the remaining moisture was removed. The mass of the prepared meal was compared to the mass of the whole seed prior to the removal of moisture and oil to obtain a correction factor unique to each sample (mass loss ranged from 24-29\%). Both the calculation of these correction factors as well as the presence of any moisture may have contributed to any discrepancy between reported and our laboratory values. 
Our methodology for extraction using methanol as previously described may also have contributed to a difference in the glucosinolate values. The ISO 9167-1 describes in detail the procedure used for extraction of glucosinolates. The most notable difference compared to our methodology is the use of boiling methanol and double extraction from each sample. The addition of boiling methanol to the solid residue that remains after centrifuging and decanting the initial supernatant liquid may provide a partial explanation for the greater glucosinolate values reported. While most compared values are similar, 4-OH benzyl glucosinolate values reported were much higher that our analyses showed. This particular glucosinolate may be sensitive to temperature of the extraction liquid or reside disproportionately in the secondary round of boiling methanol added to the solid residue after initial decantation. The report included with the certified reference material (EUR $19764 \mathrm{EN}$ ) indicates the seed having an oil content of about 40 $\%$, yet our defatting process yielded oil contents of $24-29 \%$. The values reported in this document were compiled with the use of 13 European laboratories and specifically mention the uncertainties due to the possibility of instability and lack of homogeneity.

Preliminary analysis with current methodology and instrumentation indicate general agreement with reported certified glucosinolate values except as noted above (Table 2). It thus appears that our methodology accurately reflects actual glucosinolate concentrations in the B. napus meal materials. However, standard B. napus materials do not contain either propenyl or 4-OH benzyl glucosinolate. It is thus impossible to confirm accuracy of our mustard meal analyses using the ISO standard detailed above. To our knowledge, standards for mustard meals do not exist.

We have initiated an interlaboratory comparison study with an Italian investigator (Dr. Luca Lazzeri, I.S.C.I., Via di Corticella 133, I-40129 Bologna, ITALY) to overcome this obstacle. Tissues tested to this point include only shoots and not meal. Plans to expand comparisons to include meal are in progress. Current results indeed show that our results for the same tissue materials vary substantially for both 2-propenyl and 4-OH benzyl glucosinolate. Effects of sample preparation and tissue particle size have been eliminated as possible contributors to these differences. We have not at this time determined the exact cause of the discrepancy but have isolated the difference to two possible items. First is a simple difference in the method of glucosinolate extraction. Second is a difference in the method used for calculation of glucosinolate concentrations based on detector response with respect to the analyte and the internal standard. The exact extinction coefficients for individual glucosinolates are not known with certainty. Response factors are used as multipliers to normalize the detector response of an unknown to that of the internal standard. The use of different response factors will result in drastically different glucosinolate concentration numbers. Italian investigators for an as yet unknown reason are using a different response factor for 4-OH benzyl glucosinolate than is commonly accepted. Accurate response factors must be determined, and a standard mustard material and analytical protocol established, to provide meal with a consistent pest control potential. Continued efforts in this area are necessary. 
Table 2. Glucosinolate concentration comparisons between certified values and those determined in our laboratory for four $B$. napus samples. ${ }^{1}$

\begin{tabular}{|r|c|c|c|c|}
\cline { 2 - 5 } \multicolumn{1}{c|}{} & \multicolumn{2}{c|}{$\mathbf{c 0 6 5}$} & \multicolumn{2}{c|}{ c666 } \\
\cline { 2 - 5 } \multicolumn{1}{c|}{} & Reported value & Our result & Reported value & Our result \\
\cline { 2 - 5 } & mean \pm SD & mean \pm SD & mean \pm SD & mean \pm SD \\
\hline PRO & $12.9 \pm 0.9$ & $9.6 \pm 0.2$ & $12.9 \pm 0.9$ & $9.8 \pm 0.3$ \\
EPRO & $0.34 \pm 0.07$ & tc & $0.34 \pm 0.07$ & tc \\
GNL & $0.56 \pm 0.06$ & $0.35 \pm 0.02$ & $0.56 \pm 0.06$ & $0.38 \pm 0.04$ \\
GNA & $4.1 \pm 0.4$ & $3.4 \pm 0.1$ & $4.1 \pm 0.4$ & $3.5 \pm 0.1$ \\
4OH & $3.1 \pm 0.9$ & $0.11 \pm 0.01$ & $3.1 \pm 0.9$ & $0.09 \pm 0.01$ \\
GBN & $1.45 \pm 0.17$ & $1.21 \pm 0.04$ & $1.45 \pm 0.17$ & $1.27 \pm 0.05$ \\
GBC & $0.19 \pm 0.04$ & $0.68 \pm 0.04$ & $0.19 \pm 0.04$ & $0.55 \pm 0.03$ \\
ALY & $0.091 \pm 0.006$ & tc & $0.091 \pm 0.006$ & tc \\
NEO & $0.20 \pm 0.12$ & $0.43 \pm 0.19$ & $0.20 \pm 0.12$ & $0.22 \pm 0.01$ \\
NAS & $0.15 \pm 0.07$ & tc & $0.15 \pm 0.07$ & tc \\
\hline
\end{tabular}

\begin{tabular}{|r|c|c|c|c|}
\cline { 2 - 5 } \multicolumn{1}{c|}{} & \multicolumn{2}{c|}{$\mathbf{c 6 3 5}$} & \multicolumn{2}{c|}{$\mathbf{c 6 3 9}$} \\
\cline { 2 - 5 } \multicolumn{1}{c|}{} & Reported value & Our result & Reported value & Our result \\
\cline { 2 - 5 } & mean \pm SD & mean \pm SD & mean \pm SD & mean \pm SD \\
\hline PRO & $60.7 \pm 2.7$ & $51.9 \pm 2.7$ & $60.7 \pm 2.7$ & $49.5 \pm 0.9$ \\
EPRO & $1.7 \pm 0.4$ & $1.17 \pm 0.06$ & $1.7 \pm 0.4$ & $1.01 \pm 0.01$ \\
GNL & $2.0 \pm 0.4$ & $2.0 \pm 0.1$ & $2.0 \pm 0.4$ & $1.9 \pm 0.1$ \\
GNA & $25 \pm 4$ & $23 \pm 1$ & $25 \pm 4$ & $23 \pm 0.1$ \\
4OH & $3.1 \pm 1.3$ & $0.07 \pm 0.02$ & $3.1 \pm 1.3$ & $0.07 \pm 0.01$ \\
GBN & $5.2 \pm 0.8$ & $5.2 \pm 0.2$ & $5.2 \pm 0.8$ & $5.1 \pm 0.1$ \\
GBC & $0.12 \pm 0.04$ & tc & $0.12 \pm 0.04$ & tc \\
ALY & $0.846 \pm 0.027$ & $0.761 \pm 0.044$ & $0.846 \pm 0.027$ & $0.760 \pm 0.007$ \\
NEO & $0.14 \pm 0.04$ & $0.08 \pm 0.01$ & $0.14 \pm 0.04$ & $0.09 \pm 0.01$ \\
NAS & $0.9 \pm 0.5$ & $0.07 \pm 0.01$ & $0.9 \pm 0.5$ & $0.07 \pm 0.01$ \\
\hline
\end{tabular}

${ }^{1}$ Abbreviations

\begin{tabular}{|l|l|l|l|}
\hline PRO & progoitrin & GBN & glucobrassincanapin \\
\hline EPRO & epiprogoitrin & GBC & glucobrassicin \\
\hline GNL & gluconapoleiferin & ALY & glucoalyssin \\
\hline GNA & gluconapin & NEO & neoglucobrassicin \\
\hline 4OH & 4-OH-glucobrassicin & NAS & gluconasturtin \\
\hline
\end{tabular}




\section{METHODOLOGY EFFECTS ON TOTAL GLUCOSINOLATE EXTRACTIONS}

\section{A. Introduction}

In addition to response factors as a possible stumbling block for developing a standardized method, extraction itself may play a role in the noted discrepancies. A series of experiments was performed to determine procedural modifications that might influence measured glucosinolate concentrations.

\section{B. Materials and Methods}

Five meals were prepared for glucosinolate extraction using two methodologies. The meals prepared for analysis were the pressed seed meal of "Athena" (low glucosinolate B. napus), "Dwarf Essex" (B. napus), "Pacific Gold" (B. juncea), and "IdaGold" (S. alba). We included samples from two different pressings of IdaGold seed referred to as Ida(m4) and Ida(m5) because previous HPLC analysis of IdaGold meal indicated greater variability in total glucosinolate content between different batches of meal as between replicate samples of the same batch of meal. From each of the five meals six replicate sub samples $(\sim 0.1 \mathrm{~g}$, recorded to the nearest $0.0001 \mathrm{~g}$ ) were prepared for extraction. Three replicates were used in each of the two methods. All subsamples were placed into $15-\mathrm{mL}$ vials along with $10-15$ small glass beads to help homogenization while being shaken. Vials containing the samples to be extracted using hot water (ht) were placed into a rack which was subsequently lowered into a bath of boiling water for 5 min, filled with $10-12 \mathrm{~mL}$ of hot DI water $\left(\sim 95^{\circ} \mathrm{C}\right)$, capped, agitated on a vortexer for $30 \mathrm{~s}$, and returned to a boiling water bath for an additional $10 \mathrm{~min}$. Vial samples to be extracted with methanol (me) were filled with $10-12 \mathrm{~mL}$ of methanol, capped, agitated on a vortex for $30 \mathrm{~s}$, and allowed to stand at $\sim 22^{\circ} \mathrm{C}$ for $10 \mathrm{~min}$. The analysis of the samples was then conducted as previously described.

\section{Results and Discussion}

A side by side methodology comparison was conducted to evaluate any significant difference between extracting glucosinolates by hot water $\left(\sim 95^{\circ} \mathrm{C}\right)$ or by using room temperature methanol (Fig. 1). All experimental parameters such as replicate number $(n=3)$, sample weight, internal standard type and volume, volume of extraction liquid, and agitation time were kept constant. Two different samples (m4 and m5) of IdaGold (Ida) were used in each method (ht and me). Note the greater degree of variability in total glucosinolate content with IdaGold (shown as error bars), as well as the significant difference between extraction methods for total glucosinolate content. It would thus appear that only IdaGold benefits in terms of greater total glucosinolate extraction from the use of methanol instead of hot water, while the other meals (Athena, Dwarf Essex, and Pacific Gold) yielded the same results with either method. Glucosinolate analysis of $S$. alba is thus much more susceptible to differences in extraction methods making interlaboratory comparisons more difficult. 
Figure 1. Glucosinolate concentrations in various meals as determined using hot water (ht) and methanol (me) extraction.

Comparing hot water (ht) and methanol (me) extraction

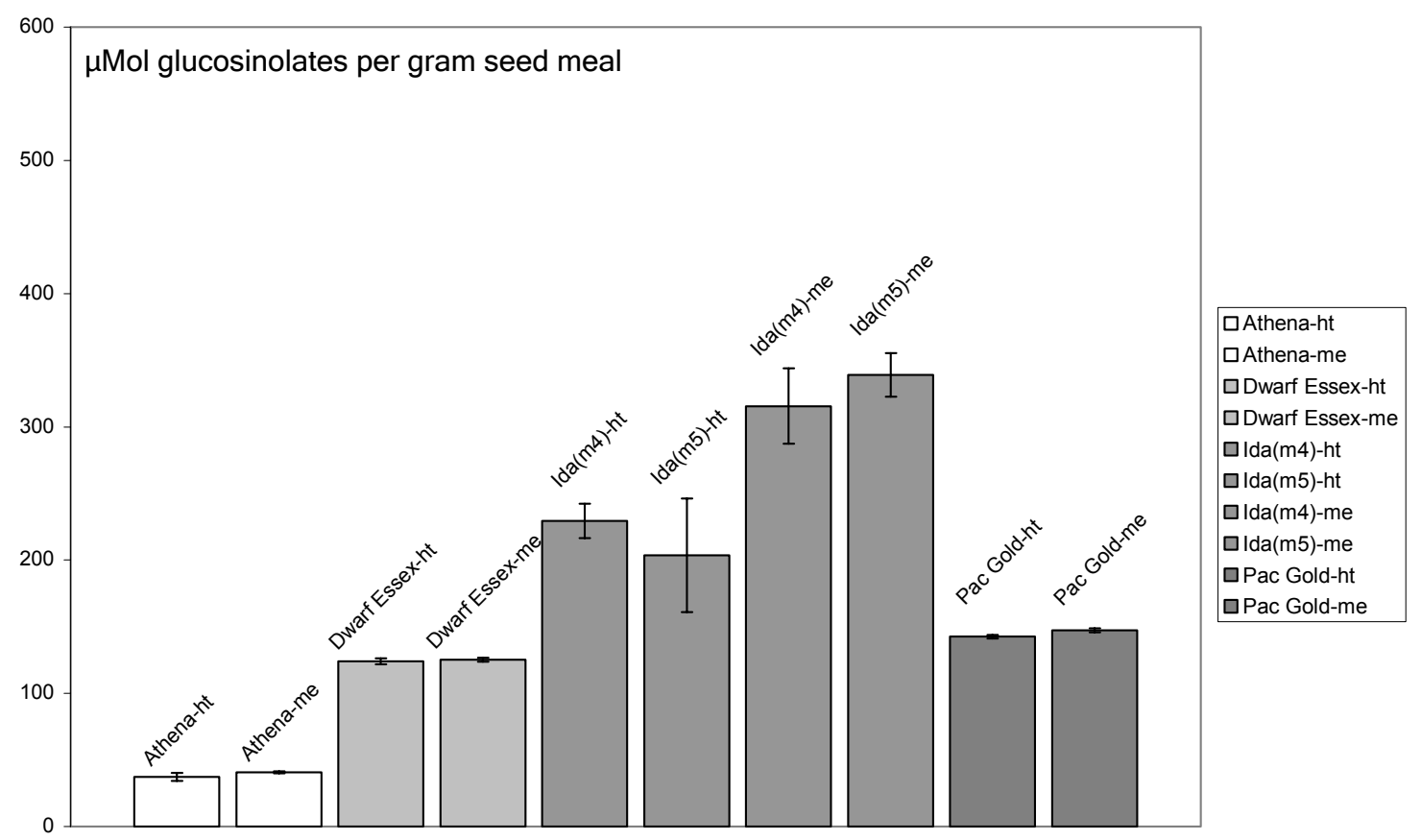




\section{EFFECT OF PROCESSING AND STORAGE}

\section{A. Introduction}

In an effort to facilitate dispersal of meal in future applications we conducted a trial pelletization of several defatted seed meals. We utilized equipment used for pelleting grains into animal feed and had a small amount of both Athena and IdaGold seed meal pressed into small pellets.

\section{B. Materials and Methods}

This process normally includes a step of exposing the stock material to high-temperature steam which aids in producing a stable pellet; however, for our purposes of retaining intact glucosinolates within the meal, we excluded this step of the procedure. The end product extruded was a relatively stable pellet with a diameter of $0.4 \mathrm{~cm}$ and a length ranging from 1-3 $\mathrm{cm}$. With this shape, these pellets would theoretically allow the material to be applied with existing equipment without the need for special modifications. Once we had obtained sample pellets we reground them into fine powder and compared the glucosinolate profile to the stock meal used to make pellets. Additionally we compared the total glucosinolate content of older stocks of Dwarf Essex, IdaGold, and Pacific Gold meal from previous harvests in 2001 to the same meals produced during 2002. This comparison was conducted to determine if significant amounts of glucosinolates were lost during storage of up to a year.

\section{Results and Discussion}

With the exception of Athena, neither the process of converting meal flakes into pellets, nor the storage of the meal for approximately a year had much effect on the total glucosinolate content (Fig. 2). The comparison of old and new stocks of Dwarf Essex, IdaGold, and Pacific Gold meal revealed little difference in composition and heterogeneity. It is likely that variability could be attributed to different environmental conditions experienced between growing seasons of the two harvests. Timing of moisture, growing degree days, and level of damage from insects could each have affected the final glucosinolate profile of the harvested seed. The process of producing pellets from the meal had no detrimental effect on the glucosinolate content, and the intense physical homogenization which occurs prior to the extrusion of the pellets appeared to decrease the final variability of total glucosinolates within the IdaGold meal. 
Figure 2. Comparison of total glucosinolates in stored, pelletized, or freshly pressed meal.

Total GLSN from stored, processed and fresh meal

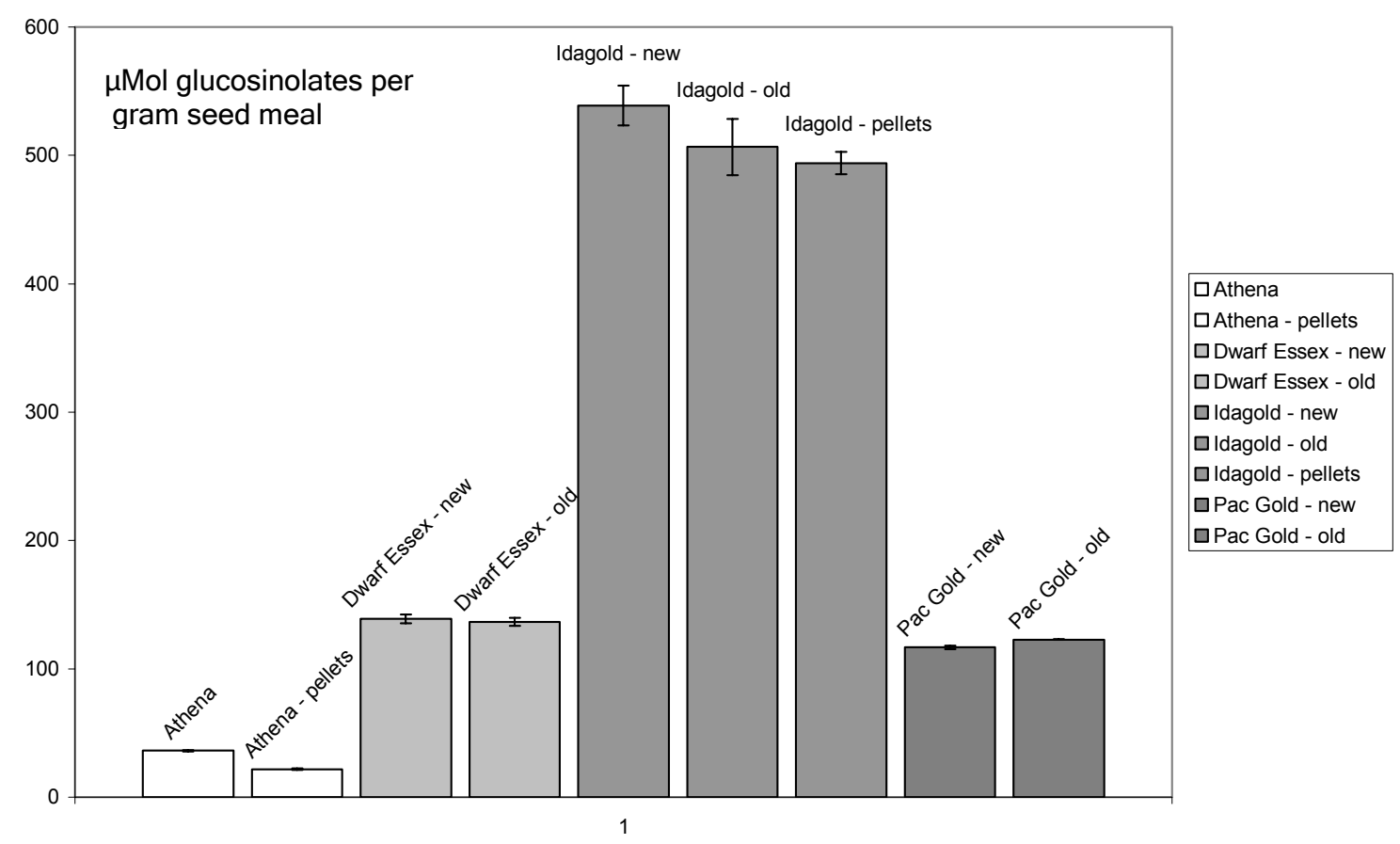




\section{ISOLATION OF GLUCOTROPEAOLIN (BENZYL GLUCOSINOLATE) FROM SEEDS OF WATER CRESS}

\section{A. Introduction}

There are two internal standards of glucosinolates currently used for analysis of seed meals from Brassicacae plants. Only one of them, 2-propenyl glucosinolate or sinigrin, is currently available on the market. Benzyl glucosinolate, or glucotropaeolin, used as internal standard for plant materials containing 2-propenyl glucosinolate was marketed by the company Merck until recently. The average market price of glucotropaeolin while commercially available was above $\$ 1$ per mg ( $\$ 1000$ per gram). Even though there are known synthetic pathways to produce some glucosinolates, a synthetic approach has never been utilized for glucosinolate production. Both glucosinolate standards on the commercial market were produced by their isolation from plant seeds. The development of an industry around the use of mustard meal will require that standards are readily available to analytical laboratories conducting quality control analyses.

\section{B. Materials and Methods}

The process of removing any oil or fat from the seed material involved mixing $500 \mathrm{~g}$ of water cress seed carefully in a blender with $2 \mathrm{~L}$ of hexane (petrolether) for $5 \mathrm{~min}$. The mixture was transferred onto a Büchner filter funnel, and the filter cake was washed twice with fresh petrolether. The filter cake was then air-dried in a fume hood. Defatted seed meal was mixed with $2 \mathrm{~L}$ of methanol-water (2:1) for $15 \mathrm{~min}$ in a blender. The mixture was transferred into a Büchner filter funnel and filter cake was washed twice with fresh methanol-water (2:1). The volume of the methanolic filtrate was reduced on rotary evaporator to approximately $1 / 3$.

The filtered seed extract was passed through a DEAE anion exchange column $(1 \mathrm{~L})$ by gravity. The column was washed with $500 \mathrm{~mL}$ of methanol and $500 \mathrm{~mL}$ of DI water, and eluted impurities were discarded. Glucotropeaolin was eluted from column with $2 \mathrm{~L}$ of $5 \%$ potassium sulfate solution in water. Volume of solution eluted from the column was reduced to approximately $100 \mathrm{~mL}$ on a rotary evaporator and diluted with $250 \mathrm{~mL}$ of methanol. Precipitated potassium sulfate was removed by filtration and the volume of filtrate was reduced to approximately $100 \mathrm{~mL}$ on a rotary evaporator. The crude extract solution remaining in evaporator flask was analyzed by HPLC. Analysis revealed it contained mainly glucotropaeoline with noticeable traces of 2-phenylethyl glucosinolate and other brown-colored unidentified impurities.

The brown-colored crude extract was passed through a C-18 preparative column $(5 \times 75 \mathrm{~cm}, 1 \mathrm{~L}$ of Amberchrome RP-C18, TOSOH BIOSEP LLC) using a methanol gradient in water from 5 to $30 \%$ and a flow rate of $25 \mathrm{~mL} \mathrm{~min}^{-1}$. The column eluant was collected in $100-\mathrm{mL}$ fractions and these fractions were analyzed by HPLC using the described procedure for glucosinolate analysis. Any fractions collected which contained impurities were discarded. The remaining fractions were merged together and freeze dried to remove any moisture or solvent. Freeze drying yielded 
$6.7 \mathrm{~g}$ of a slightly yellow powder assumed to constitute the potassium salt of glucotropaeoline. Chromatographic purity of the product was verified by HPLC using the previously described glucosinolate analysis procedure. 


\section{ISOTHIOCYANATE RELEASE FROM COLD PRESSED MEALS}

\section{A. Introduction}

Glucosinolate hydrolysis is necessary for the release of ITC, the biologically active compound responsible for pest control. Previous investigations have indicated that only a portion of the glucosinolate is actually converted to ITC. Initial efforts were thus directed towards quantifying the proportion of ITC produced relative to the original glucosinolate concentration. The effectiveness of modifying meal products to enhance ITC release can thus be determined by monitoring for an increase in release efficiency.

\section{B. Materials and Methods}

Ten grams of meal were mixed with $40 \mathrm{~mL}$ of deionized water and $10 \mathrm{~mL}$ of ethyl acetate containing $1 \mu \mathrm{L}$ decane as an internal standard. The mixture was shaken and samples were removed periodically during a time period of $96 \mathrm{~h}$. Analysis of the samples was performed used GC-MS. We used an HP 5890A gas chromatograph coupled with an HP 5972 series A mass detector, and DB-5 capillary column (30 m x $320 \mu \mathrm{m}, 0.25 \mu \mathrm{m}$ film). Ethyl acetate extracts were manually injected into a split/splitless port $\left(250^{\circ} \mathrm{C}, 20 \mathrm{sec}\right.$ split $)$, and temperature of the GC oven was programmed from $65^{\circ} \mathrm{C}$ (iso $3 \mathrm{~min}$ ) to $270^{\circ} \mathrm{C}$ (iso $5 \mathrm{~min}$ ) with a rate $15^{\circ} \mathrm{C} \mathrm{min}^{-1}$. Average linear flow rate of $\mathrm{He}$ at $250^{\circ} \mathrm{C}$ was $35 \mathrm{~cm} \mathrm{~min}^{-1}$. Quantification of data (total ion current) was performed using decane as internal standard in all samples and calibration with benzyl isothiocyanate.

Isothiocyanate release efficiency in the form of a percentage was calculated using the following equation.

$$
\text { Release efficiency }=(\text { Isothiocyanate/Glucosinolate }) \times 100
$$

Stoichiometry for glucosinolate hydrolysis shows that each mole of glucosinolate is expected to release 1 mole of ITC. Release efficiencies lower than $100 \%$ will occur when ITC amounts are less than glucosinolate amounts within the respective meal.

\section{Results and Discussion}

Fig. 3 shows the time release curve for propenyl ITC from B. juncea Pacific Gold meal. Maximum ITC release of $88 \mu \mathrm{mol} \mathrm{g}{ }^{-1}$ seed meal occurred at $10 \mathrm{~h}$. This amount of ITC is equivalent to a release efficiency of $80 \%$. Thus $80 \%$ of the glucosinolate potentially available was actually measured as ITC. Fig. 3 also shows the ITC release curves for $S$. alba IdaGold and B. napus Dwarf Essex. The ITC release efficiency from $S$. alba IdaGold is $29 \%$ and that for $B$. napus Dwarf Essex is 65\%. Increased released efficiencies will translate into more effective pest 
control. It must be noted that any inaccuracies in glucosinolate concentrations will translate into inaccurate release efficiency calculations.

Release efficiency data indicate that little benefit may exist for attempting to enhance propenyl release from $B$. juncea meal. Greater benefit may be realized by increasing ITC release from $S$. alba meal since the release efficiency was only $29 \%$. However, the meal already contains high 4-OH benzyl concentrations that may reduce the need for such enhancement. In addition, it is quite possible in the case of $S$. alba that release efficiency is not the only contributing factor to the measured low ITC concentrations. It must be remembered that measured concentrations will be a function of opposing ongoing processes that include both ITC production and ITC

dissipation. In the case of $S$. alba, dissipation may occur at a relatively high rate, thus decreasing the mass of ITC accumulating in the medium. This aspect of the topic is addressed below. 
Figure 3. Isothiocyanate (ITC) formation from three meal products.
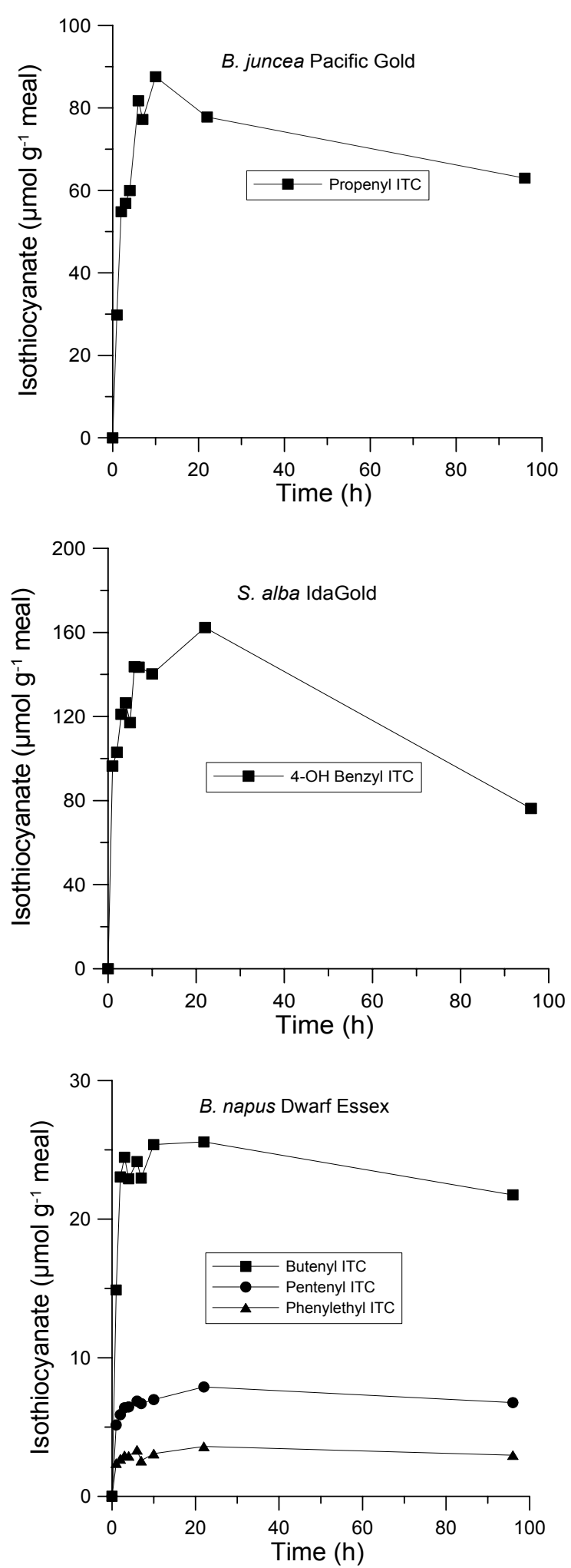


\section{ADDITIONAL GLUCOSINOLATE HYDROLYSIS PRODUCTS}

\section{A. Introduction}

The lack of a biological response with $S$. alba meal was puzzling given the fact that this meal contained the highest concentration of what we thought was a glucosinolate that produced ITC, 4-OH benzyl. Literature indicates that this ITC is stable unless subjected to strong alkali, at which time it is hydrolyzed and $\mathrm{SCN}^{-}$is formed. Release efficiency data indicate that such thinking may not accurately reflect 4-OH benzyl ITC behavior.

\section{B. Materials and Methods}

We tested the $\mathrm{pH}$ stability of 4-OH benzyl ITC by incubating it in 5 buffers (sodium acetate/acetic acid from $\mathrm{pH}$ range 3 to 5 and monosodium phosphate/ phosphatic acid for $\mathrm{pH}$ above 5) with pHs ranging from 3.0 to 7.0. At specific times during the incubation a sample from the incubated solution was withdrawn with a syringe and injected into a HPLC-PDA (Waters Integrity system, separation module 2695, photodiode array detector 996, column Phenomenex Aqua C-18, $5 \mu \mathrm{m}, 150 \times 2 \mathrm{~mm}$, with a constant flow rate of $200 \mu \mathrm{L} \mathrm{min}{ }^{-1}$, gradient from 5 to $35 \%$ of methanol in $30 \mathrm{~min}$ ). The amount of 4-OH benzyl ITC was determined using calibration with benzyl ITC.

Table 3. Stability of 4-OH benzyl ITC at different pHs.

$\begin{array}{cc}\mathrm{pH} & \text { Half-life (min) } \\ 3 & 216 \\ 4 & 126 \\ 5 & 90 \\ 6 & 6 \\ 7 & 4.8\end{array}$

\section{Results and Discussion}

We determined that 4-OH benzyl isothiocyanate was not stable even at $\mathrm{pH}$ values of 3.0. The half-life decreases with an increase in $\mathrm{pH}$ from $3.6 \mathrm{~h}$ at $\mathrm{pH} 3.0$ to less than $5 \mathrm{~min}$ at $\mathrm{pH} 7.0$ 
(Table 3). Thus in a soil environment 4-OH benzyl ITC will be produced in S. alba meal but because it is unstable, will hydrolyze rapidly. The proposed pathway is shown below.

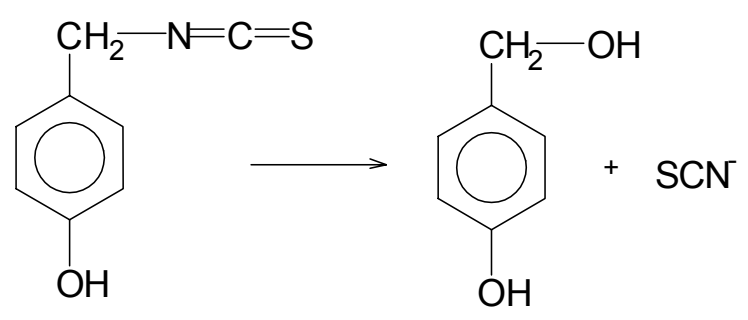

It thus is likely that the lack of a negative effect on insects, nematodes, and fungi is caused by the rapid hydrolysis of 4-OH benzyl ITC. This instability may also contribute to the low release efficiencies that were measured. However, the fact that $S$. alba meal is an effective herbicide indicates that one of the hydrolysis products is responsible. Literature indicates that $\mathrm{SCN}^{-}$is indeed phytotoxic and thus of likely importance in weed inhibition. We will determine if $\mathrm{SCN}^{-}$ is produced in amounts that correspond with the above stoichiometry.

\section{CONCLUSIONS AND RECOMMENDATIONS}

1. Standard procedures must be developed for the analysis of glucosinolates in mustard meals. Such procedures should mirror those currently available for B. napus seed materials.

2. A repository of mustard seed should be established and made available to those conducting glucosinolate analyses. Certified analysis of the individual glucosinolates should be provided using the standardized procedure.

3. Internal standards must be made commercially available to all laboratories involved in glucosinolate analysis.

4. An accepted set of response factors must be established and uniformly applied by those laboratories measuring glucosinolates.

5. Items 1-4 must be in place in order to ensure a mechanism for quality control of meal products to be used in pest control.

6. S. alba meal presents the greatest problem with respect to precisely measuring glucosinolate concentrations in meal products.

7. Pelletized meal products represent a viable option for formulation since glucosinolate concentrations are not affected by the extrusion procedure.

8. Meal products may be stored with little glucosinolate loss.

9. Adjuvants are not necessary for increased release of ITC from B. juncea meal.

10. Low ITC concentrations as measured for $S$. alba meal are most likely a function of high ITC conversion rates to $\mathrm{SCN}^{-}$.

11. Herbicidal activity of $S$. alba meal is probably a consequence of $\mathrm{SCN}^{-}$production. 


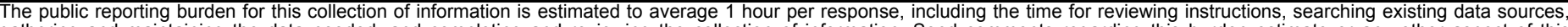

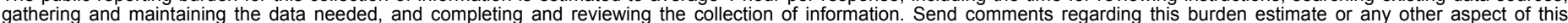

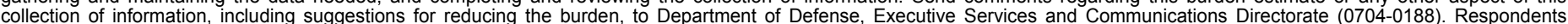

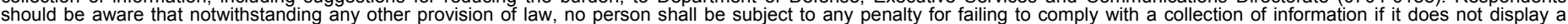

should be aware that notwithstanding

PLEASE DO NOT RETURN YOUR FORM TO THE ABOVE ORGANIZATION. \begin{tabular}{l|l|l}
\hline $\begin{array}{l}\text { REPORT DATE (DD-MM-YYYY) } \\
\text { July } 2005\end{array}$ & 2. $\begin{array}{l}\text { REPORT TYPE } \\
\text { Subcontract Report }\end{array}$ & $\begin{array}{l}\text { DATES COVERED (From - To) } \\
2000-2002\end{array}$ \\
\hline
\end{tabular}

4. TITLE AND SUBTITLE

Chemical Characterization and Release Efficiency of Defatted

Mustard Meals: 2000-2002 5a. CONTRACT NUMBER

DE-AC36-99-GO10337

5b. GRANT NUMBER

5c. PROGRAM ELEMENT NUMBER

5d. PROJECT NUMBER

NREL/SR-510-36208

5e. TASK NUMBER

FC059400

5f. WORK UNIT NUMBER
7. PERFORMING ORGANIZATION NAME(S) AND ADDRESS(ES)

University of Idaho

Moscow, Idaho
8. PERFORMING ORGANIZATION REPORT NUMBER

XC0-9-29095-01

9. SPONSORING/MONITORING AGENCY NAME(S) AND ADDRESS(ES)

National Renewable Energy Laboratory

10. SPONSOR/MONITOR'S ACRONYM(S) NREL

1617 Cole Blvd.

Golden, CO 80401-3393

11. SPONSORING/MONITORING AGENCY REPORT NUMBER NREL/SR-510-36208

12. DISTRIBUTION AVAILABILITY STATEMENT

National Technical Information Service

U.S. Department of Commerce

5285 Port Royal Road

Springfield, VA 22161

13. SUPPLEMENTARY NOTES

NREL Technical Monitor: K. Shaine Tyson

14. ABSTRACT (Maximum 200 Words)

Glucosinolates, compounds that occur in agronomically important crops, may represent a viable source of allelochemic control for various soil-borne plant pests. Toxicity is not attributed to intact glucosinolates, but instead to biologically active products such as isothiocyanates (ITCs), organic cyanides, oxazolidinethiones, and ionic thiocyanate (SCN-) released upon enzymatic degradation by myrosinase (thioglucoside glucohydrolase, EC 3.2.3.1) in the presence of water.

15. SUBJECT TERMS

mustard meal; allelochemical; glucosinolates

16. SECURITY CLASSIFICATION OF:
\begin{tabular}{|l|l|l|}
\hline a. REPORT & b. ABSTRACT & c. THIS PAGE \\
Unclassified & Unclassified & Unclassified \\
& & \\
\hline
\end{tabular}

\begin{tabular}{|c|c|}
\hline $\begin{array}{l}\text { 17. LIMITATION } \\
\text { OF ABSTRACT }\end{array}$ & $\begin{array}{l}\text { 18. NUMBER } \\
\text { OF PAGES }\end{array}$ \\
\hline UL & \\
\hline
\end{tabular}

19a. NAME OF RESPONSIBLE PERSON

19b. TELEPHONE NUMBER (Include area code) 